\title{
Public sentiment in China cools towards Australia
}

Edition 7, 2021

Assistant Professor Dan (Diane) Hu

DOI: 10.37839/MAR2652-550X7.3

Public sentiment in China has cooled towards Australia, underscoring the deteriorating relations between the two countries, according to a 2021 annual poll of Chinese attitudes towards the country.

Commissioned by the Australian Studies Centre at Beijing Foreign Studies University, we ran the inaugural poll in June 2020 in partnership with the Global Times Research Centre and Data 100, a well-established Chinese social and market research company. It was the first public poll on Chinese attitudes towards Australia, and this second iteration shows that public sentiment has shifted downwards.

When respondents were asked to rate their feelings towards selected countries with any number from zero to 100, Australia fell from a score of 65.28 in 2020 to 55.61 this year. In last year's poll, 7.6 percent of respondents picked Australia as 'China's best friend' from 14 selected countries, but this year that proportion is down to just 4.5 percent.

In this year's poll, there was a 17 percent decrease in the proportion of respondents picking Australia as a popular travel and education destination. Australia ranked fourth among 12 selected countries this year as 'the country you want to travel to' down from second in 2020 as the proportion of respondents choosing Australia fell from 16.7 per cent to 13.6 per cent.

Similarly, this year only 13.6 percent of respondents chose Australia as 'the country you want to study in', down from 16.5 percent in 2020. 
What appears to be more concerning is a continued redefinition of what Australia means to China. Last year two-thirds (66.8 percent) of respondents defined Australia as 'more of an economic partner to China', but this group shrank to 58.7 percent this year.

Similarly, the proportion of respondents who see Australia as 'more of a political or ideological threat to China' increased by five percent to over one third ( 34.2 percent). Responses that classified Australia as 'more of a military threat' doubled to 7.1 percent.

The poll results from 2020 and 2021 confirm our previous observations that among the Chinese public there are conflicting perceptions of Australia. On the one side, the Chinese see Australia as one of the top destinations for education, travel and migration - a place of cuddly koalas, beef, wine and sunny beaches. But on the other side is a perception that Australia is 'a lapdog of the U.S.', to quote one of the most often used terms.

Now, as tensions grow between China and Australia, the Chinese public are finding it more difficult to reconcile these two dominant perceptions of Australia, which has serious and real implications for Australian businesses and universities.

Some of the questions in our poll mirror those adopted for the Lowy Institute's annual poll that also covers the attitudes of Australians towards China and has been running since 2005 .

It is important to note that while the Lowy poll, and probably also University of Technology Sydney's (UTS) poll on Australian attitudes to China, are intend to be nationally representative, while our poll concentrates on middle and upper-middle income earners in China. Out of 2,067 respondents, 76.3 percent were middle $(\$ A 1,000$ to $\$ A 1,599)$ to high income earners and 68.17 percent had a bachelor's degree or above.

They are also concentrated in ten top Chinese cities - Beijing, Chengdu, Guangzhou, 
Kunming, Qingdao, Shanghai, Shenyang, Wuhan, Xi'an and Zhengzhou.

According to China's most recent census and other related statistics and research, only 11.3 per cent of the national population fall into the middle-and-high income group and only 15.5 per cent have a bachelor degree or above.

Both this year's results, and last year's, indicate a close correlation between income and education level and attitudes towards Australia. The lower a respondent's income and educational attainment, the stronger the degree of negativity towards Australia. In other words, if the poll result is to be adjusted to be nationally representative, it would almost certainly be more negative, possibly by a significant margin.

For example, if education-related adjustment is made on the 2020 result, based on census results of the same year, Australia would score just 55.44 out of 100 in 'warm feelings', and this year's result, after adjustment, would be somewhere between 40 and 47 out of 100 .

This isn't much more favourable than the frosty attitudes of Australians to China as found in the Lowy Institute's poll where the warmth of feeling towards China score was just 32 out of 100 .

It is also important to note that the Lowy poll, the UTS poll and our poll were conducted at different times of the year.

Our poll was conducted 11-15 June 2021. In contrast, the Lowy and UTS polls collected their responses from mid-March to mid-April, amid China imposing antidumping and countervailing duties on Australian wine, a key meeting between China and the US, Quad meetings in March, and Australian statements on Xinjiang and Hong Kong among other developments.

In comparison, the week in mid-June was almost uneventful in terms of bilateral relations. 
Digging deeper into our poll results we find that while 45.6 percent of respondents named the US as the biggest impediment to bilateral relations between Australia and China, that has actually decreased from 49.5 per cent last year.

Ideological differences between the two nations was listed by 35.4 percent of respondents as the main barrier to better bi-lateral relations, up from 32.5 percent last year, and 15.9 percent of respondents believe that these ideological differences have been affected by Australian domestic politics, slightly up from last year.

This perhaps reflects a more nuanced understanding of Australia and its China policy rather than respondents assuming that Australia simply represents U.S. interests; though China may very well continue to have a U.S.-focused world view and read Australia's China policy through that lens.

When asked to predict if China's relations with Australia will improve, an encouraging 43.3 percent say they expect bilateral relations to improve, compared with almost 34.7 per cent not expecting relations to improve, and 22 per cent finding it 'hard to say'.

One policy option that seems to have some support is the two countries 'jointly funding aid programs in Asia and the Pacific', with 53.4 percent of respondents supporting that proposition, 21.4 percent against and almost 22.5 percent expressing a neutral position.

Interestingly, a common trend in both our poll and Lowy's poll is that positive feelings by one public towards the other seems to be age-relevant. The under-30s stand out as the age group with the warmest feelings toward each other in both surveys.

Maybe that bodes well for the future of China-Australia relations.

Dr Hu is Lead Investigator on the poll.

Image: Shoppers in Shanghai. Credit:_ChrisUK/Flickr. 